Supplement of

\title{
Enhancement of secondary aerosol formation by reduced anthropogenic emissions during Spring Festival 2019 and enlightenment for regional $\mathbf{P M}_{2.5}$ control in Beijing
}

Yuying Wang et al.

Correspondence to: Yuying Wang (yuyingwang@ nuist.edu.cn)

The copyright of individual parts of the supplement might differ from the CC BY 4.0 License. 


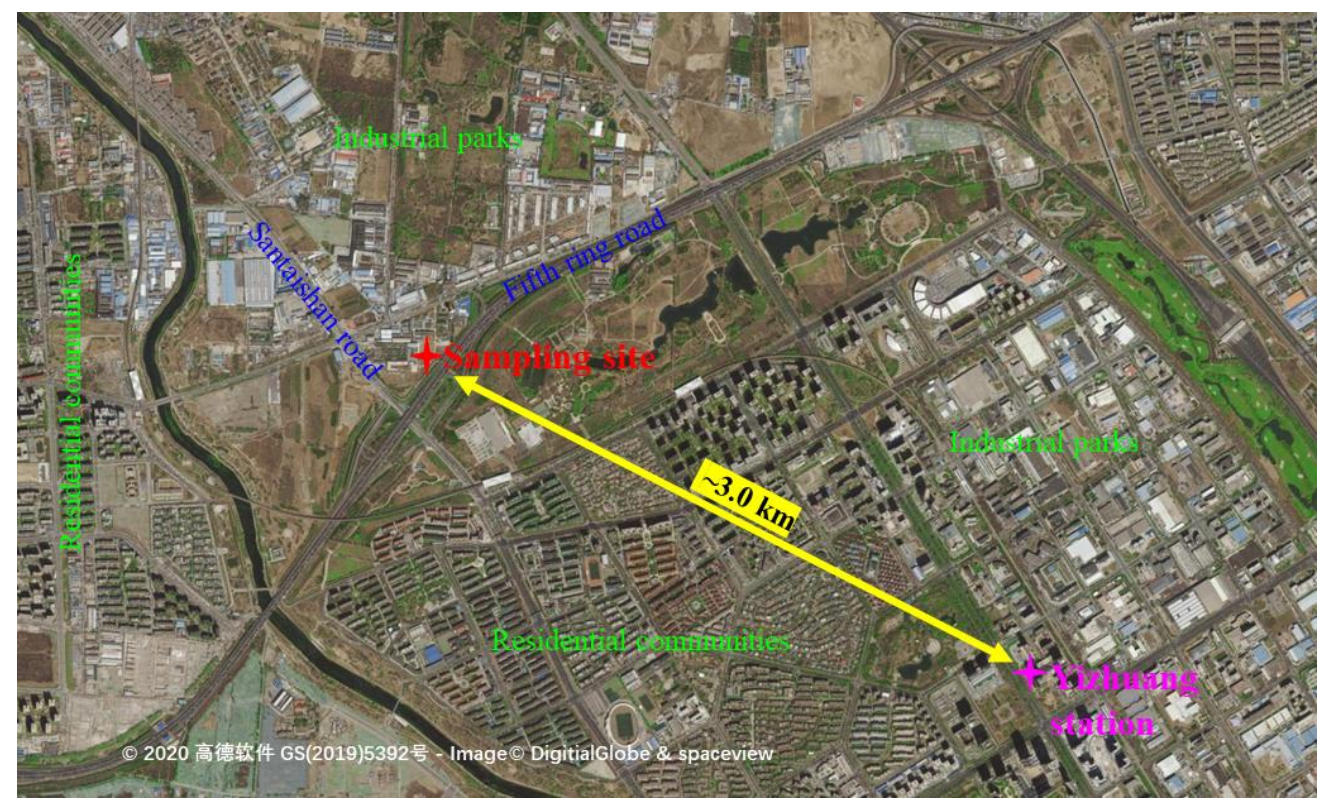

Figure S1. A true color image showing the locations of the sampling site and Yizhuang station, and their surrounding landscapes.

As shown in Fig. S2, $\mathrm{PM}_{2.5}$ mass concentrations measured during the field campaign (the combination of non-refractory aerosol chemical species and BC measured by the ACSM and the AE-33) overall tracks well with observed $\mathrm{PM}_{2.5}$ mass concentrations at the Yizhuang station. Some deviations are likely related to short-term local emissions. The general agreement between the two sets of $\mathrm{PM}_{2.5}$ mass concentrations is further demonstrated by the correlation analysis (inset scatter plot).

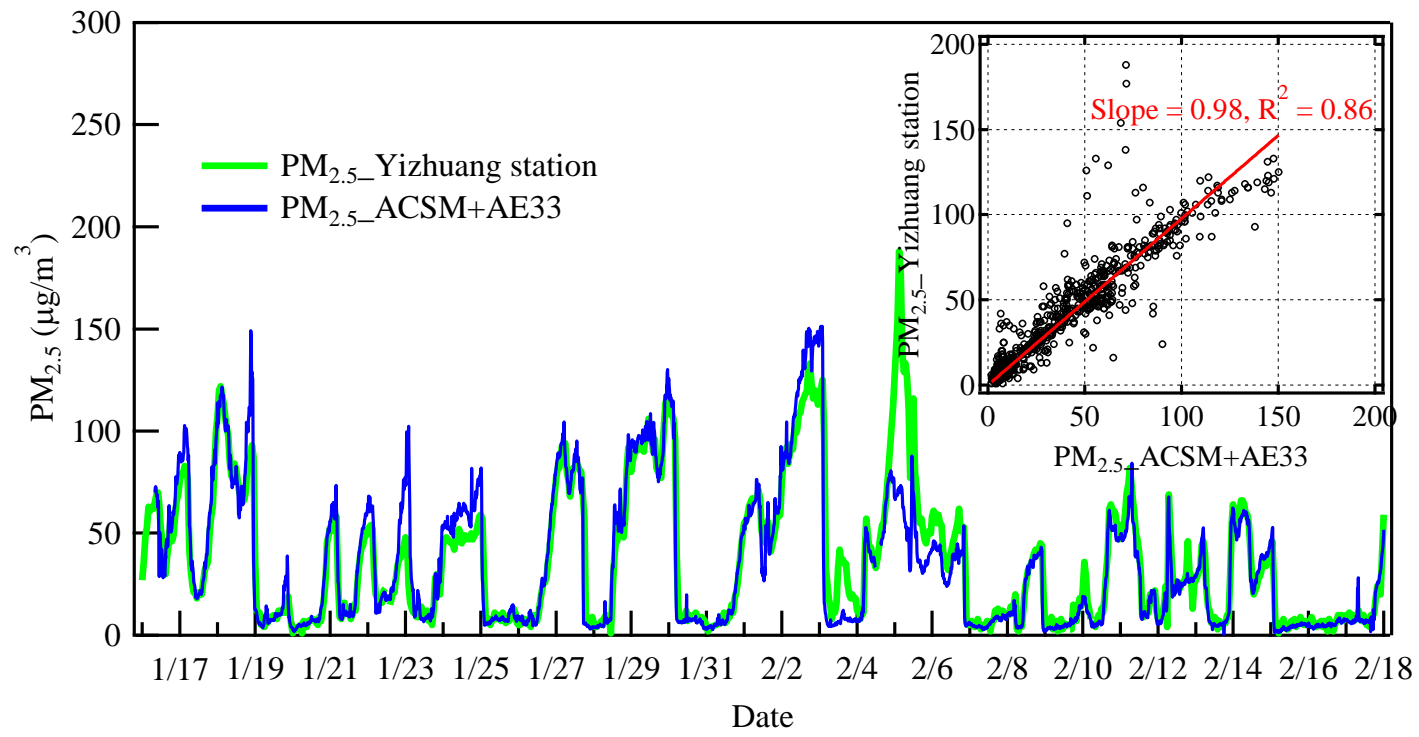

Figure S2. Time series of the total mass concentration of aerosol chemical species measured by the ACSM and the AE-33 (blue curve) and the $\mathrm{PM}_{2.5}$ mass concentration observed at the Yizhuang station (green curve). The scatter plot shows the correlation analysis of these mass concentrations, where the red line is the best-fit line from linear regression. 

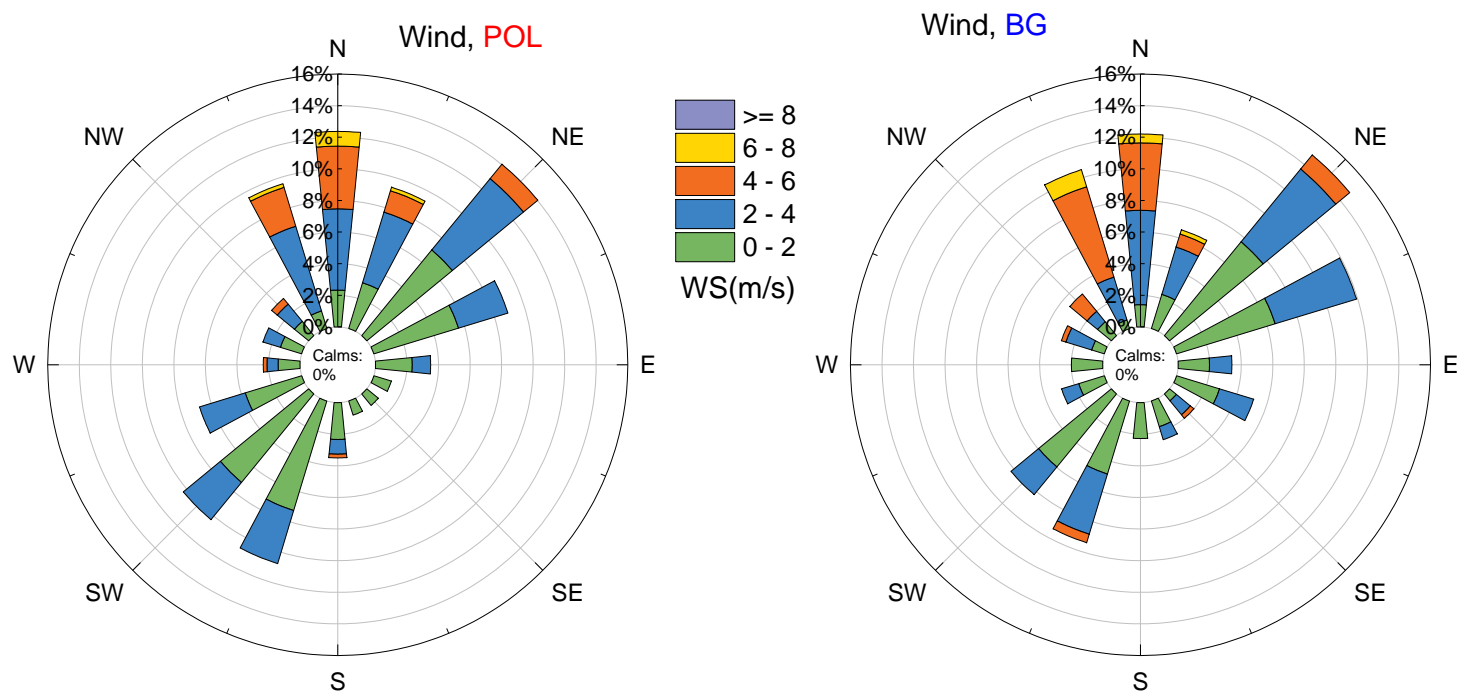

Figure S3. Wind rose diagrams of wind directions (WD) and wind speed (WS) during the POL (left diagram) and BG (right diagram) periods.

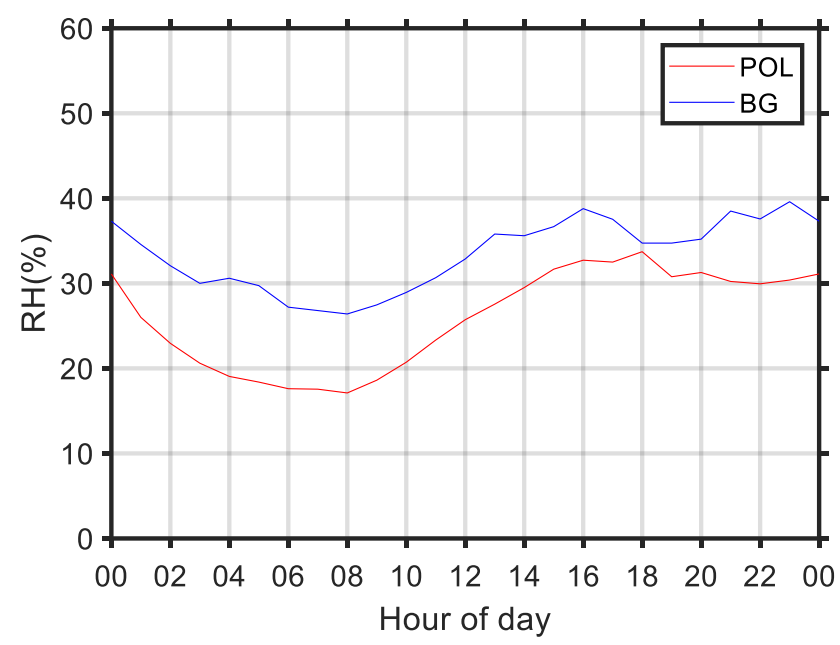

Figure S4. Diurnal variation of ambient relative humidity $(\mathrm{RH})$ during the POL and BG periods. 


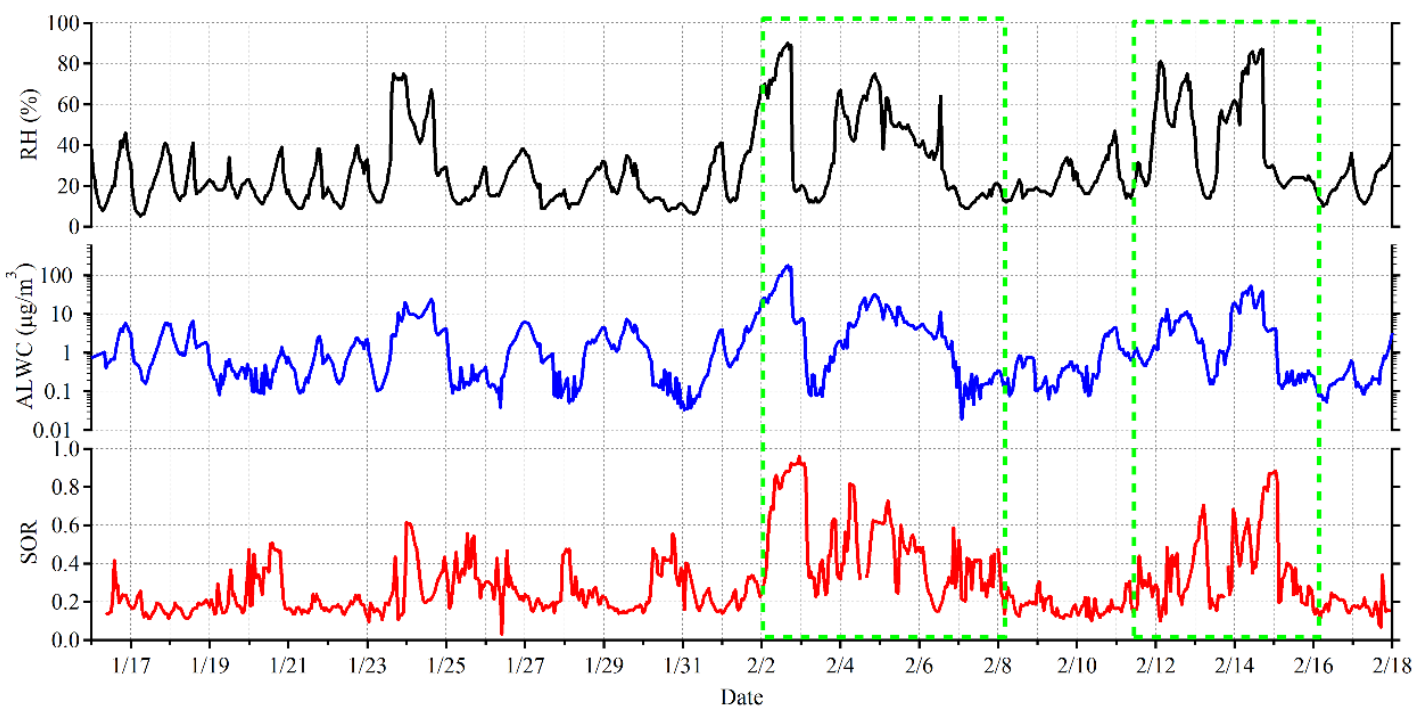

Figure S5. Time series of relative humidity $(\mathrm{RH})$, aerosol liquid water content (ALWC) calculated according to aerosol chemical species using the ISORROPIA II model, and the sulfur oxidation ratio (SOR). The green dashed boxes show when SOR increased following an increase in ALWC when the ambient RH was higher than $\sim 40 \%$ during the BG period. 